\title{
A fuzzy inference based method for evaluating coordinated generation-grid-load-storage control ability in receiving-end power system
}

\author{
Lu Yang ${ }^{1}$, Yuanyang Chen ${ }^{2}$, Yijia Cao ${ }^{1}$, Changfeng $\mathrm{Liao}^{1 *}$, Yi Tan ${ }^{1}$, Yong $\mathrm{Li}^{1}$, and Siyuan $\mathrm{Guo}^{3}$ \\ ${ }^{1}$ College of Electrical and Information Engineering, Hunan University, Changsha, Hunan 410082, China \\ ${ }^{2}$ State Grid Hunan Electric Power Company Limited, Changsha, Hunan 410004, China \\ ${ }^{3}$ Electric Power Research Institute, State Grid Hunan Electric Power Company Limited, Changsha, Hunan 410007, China
}

\begin{abstract}
With the rapid development of the flexible loads and energy storage, it is of great scientific and engineering value to improve safety and economy of the receiving-end power system with HVDC feed-in power by the coordinated generation-grid-load-storage control. In this paper, a fuzzy inference based method is proposed to assess the coordinated control ability of generation-grid-load-storage control for the receiving-end power system with HVDC feed-in power. First of all, the evaluation indexes are constructed with consideration of the coordination and interaction of power generation, power grid, power load and energy storage. Both subjective weight and objective weight are considered to calculate the comprehensive weight for each evaluation index. Furthermore, the Kmeans clustering based method is proposed to the grading in each evaluation index. Finally, the coordination control ability of the modified IEEE 57-bus system in different states is evaluated by the proposed method.
\end{abstract}

\section{Introduction}

The line commutated converter based high-voltage direct current transmission system (LCC-HVDC) is a solution to the efficient, safe and long-distance transmission of large scale energy [1]. The renewable energy fed into the receiving-end system via HVDC technology can greatly reduce the power supply pressure, but it also brings the adverse effects to the safe and stable operation of the receiving-end power system [2]. For example, the DC blocking can cause a large-scale power shortage in the receiving-end power system and traditional stability control methods such as the load shedding are difficult to work effectively in this situation [3]. The interaction and coordinated operation of power generation, power grid, power load and energy storage (denoted as generationgrid-load-storage in this paper) is very conducive to the dynamic supply-demand balance and the economic and safe power system operation [4]. Thus, this helps to improve the stability and security level of the receivingend power system with HVDC feed-in power.

Research work has been done in the field of the generation-grid-load-storage optimization and control. Ref. [5] proposed an integrated generation-grid-loadstorage operation method to realize the efficient operation of park microgrid by considering market transaction, auxiliary services and so on. With consideration of the operating costs, initial investment costs, pollutant emission costs, Ref. [6] proposed a cultural genetic algorithm based generation-grid-load- storage scheduling method for hybrid AC/DC microgrid. Ref. [7] proposed a genetic algorithm based multi-period coordinated generation-grid-load-storage dispatch method for active distribution networks. Ref. [5-7] mainly focused on the coordinated generation-grid-loadstorage control and optimization in small-scale power systems to reduce the operating costs. In contrast, Ref. [8] proposes a multi-objective generation-grid-load-storage dispatch method to reduce the costs and pollutant emissions by coordinating various controllable resources in bulk power systems.

With the rapid development of the fine load shedding, battery storage, the coordinated generation-grid-loadstorage optimization and control are increasingly being emphasized by the academic community and the power industry. Consequently, it is necessary to research on the effective and reasonable assessment of the coordinated control ability of power generation, power grid, power load and energy storage. Thus, this paper presents the evaluation indexes by comprehensive consideration of the generation-grid-load-storage characteristics in the receiving-end power system with HVDC feed-in power. Also, this paper proposes the fuzzy inference based method for assessing the coordinated generation-gridload-storage control ability.

\section{Indexes for evaluation}

This section proposes the evaluation indexes for the coordinated generation-grid-load-storage control 
(GGLSC) ability in the receiving-end power system with HVDC feed-in power.

\subsection{Fast frequency control}

Thermal generating units and hydropower units are traditional frequency-control units in power systems. It is well known that thermal generating units have limited ramping rate and slow response speed and the water supply of hydropower generating units is unstable. The battery storage has fast response speed and flexible adjustment ability which can realize fast frequency control [9].

Considering the rapid response characteristics of the battery storage, the fast frequency control ability $\left(T_{F F M A}\right)$ is defined as follows.

$$
T_{F F M A}=\frac{\alpha_{c h}^{\prime} P_{c h}^{\prime}}{P_{L}}+\frac{\beta_{d i s}^{\prime} P_{d i s}^{\prime}}{P_{L}}
$$

where $P_{c h}^{\prime}$ is the fast charging power of the battery storage and $P_{d i s}^{\prime}$ is the fast discharging power of the battery storage. $P_{L}$ is active power demand of the receiving-end power system. $\alpha_{c h}^{\prime}$ is the weight coefficient of the fast charging of the battery storage, and $\beta_{d i s}^{\prime}$ is the weight coefficient of the fast discharging power of the battery storage.

\subsection{Total frequency control ability}

By considering the frequency control ability of thermal power units, hydropower units and battery storage [10], and the total frequency control ability $\left(T_{T F M A}\right)$ of the receiving-end power system is defined as follows:

$$
\begin{gathered}
T_{T F M A}=T_{T F M A}^{h}+T_{T F M A}^{s}+T_{F F M A} \\
T_{T F M A}^{h}=\frac{\alpha_{u}^{h} P_{u}^{h}+\beta_{d}^{h} P_{d}^{h}}{P_{L}} \\
T_{T F M A}^{s}=\frac{\alpha_{u}^{s} P_{u}^{s}+\beta_{d}^{s} P_{d}^{s}}{P_{L}}
\end{gathered}
$$

where $T_{T F M A}^{h}$ is the frequency control ability of the thermal units. $P_{u}^{h}$ is the ramping-up power of the thermal units. $P_{d}^{h}$ is the ramping-down power of the thermal units. The $\alpha_{u}^{h}$ and $\beta_{d}^{h}$ are the weight coefficients of the $P_{u}^{h}$ and $P_{d}^{h}$, respectively. $T_{T F M A}^{s}$ is the frequency control ability of hydropower units, $P_{u}^{s}$ is the ramping-up power of hydropower units, $P_{d}^{s}$ is the ramping-down power of hydropower units. The $\alpha_{u}^{s}$ and $\beta_{d}^{s}$ are the weight coefficients of $P_{u}^{s}$ and $P_{d}^{s}$, respectively.

\subsection{Peak load adjustment}

Considering the peak-load adjustment ability of thermal power units, hydropower units and energy storage systems [11], the peak-load adjustment ability $\left(\psi_{P L R A}\right)$ is defined as follows:

$$
\psi_{P L R A}=\frac{R_{b}^{h}+R_{b}^{s}}{P_{L}}+\frac{2 C_{b}^{x}}{T_{p} P_{L}}
$$

where $R_{b}^{h}$ is the reserve capacity of the thermal units. $R_{s}^{b}$ is the reserve capacity of the hydropower units. $C_{b}^{x}$ is the rated energy of the battery storage, and $T_{p}$ is the total time for the battery storage to participate in peakload adjustment.

\subsection{HVDC feed-in Power}

This paper assumes that external renewable energy such as remote wind power are fed into the receiving-end power system via HVDC. The characteristics of the wind power that transmitted by HVDC can reflect the stable level of the receiving-end system and the coordinated GGLSC ability to a certain extent [12]. Thus, the following index related to wind power that transmitted by HVDC is proposed to evaluate the coordinated GGLSC ability of the receiving-end power system:

$$
\gamma_{W G}=\alpha_{u n c} \frac{P_{L}}{P_{L C C, \text { Wind }}}+\beta_{\text {adj }} \lambda_{\text {adj }} P_{L C C, \text { Wind }}
$$

where the first part on the right side of (6) reflects the uncertainty of wind power, and the latter part reflects the adjustment ability of wind power. $P_{L C C, \text { Wind }}$ is the wind power transmitted via HVDC. $\alpha_{u n c}$ and $\beta_{a d j}$ are the coefficient weights to determine the importance of wind power uncertainty and wind power controllability, respectively. $\lambda_{a d j}$ is a coefficient reflecting the relationship between the controllability and wind power.

\subsection{Reactive power support}

The reactive power support from the receiving-end power system can reduce the probability of unipolar blocking of HVDC converters [13]. In this paper, the reactive power support ability is defined as follows:

$$
\varepsilon_{z}=\frac{Q^{t}+Q^{h}+Q^{s}+Q^{x}}{Q_{L}+Q^{H V D C}}
$$

where $Q^{t}$ is the reactive power output of the synchronous condenser. $Q^{h}$ and $Q^{s}$ represent the reactive power outputs of thermal and hydroelectric power plants, respectively. $Q^{x}$ is the reactive power output of the battery storage. $Q^{H V D C}$ is the reactive power absorbed by the HVDC system. Since the quantity of $Q^{H V D C}$ is equal about $40 \%$ of the quantity of the active power of the HVDC system [14], $Q^{H V D C}$ is 
assumed to be $40 \%$ of the active power of the HVDC system in quantity in this paper. Also, it is assumed that $50 \%$ of the active power transmitted by HVDC comes from external wind power and the rest is from external thermal power plants. $Q_{L}$ represents the reactive load within the receiving-end power system.

\subsection{Voltage stability}

The stability level reflects how effective the coordinated GGLSC will be to a certain extent [15]. In order to consider the voltage stability margin of the $\mathrm{AC}$ bus that the HVDC converter is connected and the voltage stability margin of other buses in the receiving-end power system, the following voltage stability index are proposed:

$$
\delta^{c}=\alpha_{V} \frac{V_{H V}-V_{\mathrm{HV}, c r}}{V_{H V}}+\beta_{V} \max _{i}\left\{\frac{V_{i}-V_{i, c r}}{V_{i}}\right\}
$$

where $V_{H V}$ is the voltage of the AC bus that the HVDC converter is connected. $V_{H V, c r}$ is the well-known critical voltage of the PV curve of the AC bus that the HVDC converter is connected. $V_{i}$ and $V_{i, c r}$ represent the voltage and the well-known critical voltage of the PV curve of bus $i$ (except the AC bus that the HVDC converter is connected) in the receiving-end power system. $\alpha_{V}$ and $\beta_{V}$ are the weight coefficients for considering different parts of the receiving-end power system.

\subsection{Rough load shedding and fine load shedding}

Rough load shedding (RLS) and fine load shedding (FLS) reflect the stability control ability of flexible load [16]. The shedding precisions of the RLS and the FLS are different, thus this paper proposes the weighting of the RLS and the FLS to evaluate the coordinated GGLSC ability:

$$
v_{k}=\frac{\alpha_{m} L_{m}+\beta_{j} L_{j}}{P_{L}}
$$

where $L_{m}$ is the load that the RLS system can shed, and $L_{j}$ represents the load that the FLS system can shed. The $\alpha_{m}$ and $\beta_{j}$ are the weights of RLS and FLS, respectively.

\section{Comprehensive evaluation method based on fuzzy inference}

\subsection{Fuzzy inference}

Fuzzy inference based evaluation can make a comprehensive assessment by considering many factors, thus it is widely used in power system evaluation, control and other fields [17]. Fuzzy logic generally contains four parts, i.e., fuzzification, fuzzy rules, fuzzy inference, and defuzzification [18]. In this paper, the coordinated GGLSC ability evaluation is based on the widely used Mamdani fuzzy reasoning [19]. When the input is $A$, Mamdani-type fuzzy inference calculates the output $B$ as follows:

$$
B=A \circ(C \rightarrow D)
$$

where $C \rightarrow D$ and $\circ$ represent fuzzy rules and fuzzy operation, respectively. $A$ is the membership matrix for the fuzzified evaluation indexes and $B$ is the evaluated grade of the result. The fuzzy membership function of the Mamdani operation is

$$
\mu_{B}(y)=\vee_{x \subset X} \mu_{A}(x) \wedge\left[\mu_{C}(x) \wedge \mu_{D}(y)\right](11)
$$

The fuzzy rules used in this paper can be expressed in Figure 1, where $x_{1}, x_{2}, x_{3}, x_{4}, x_{5}, x_{6}$ and $x_{7}$ correspond to the evaluation indexes $T_{F F M A}, T_{T F M A}, \psi_{P L R A}, \gamma_{W G}, \varepsilon_{z}$, $\delta^{c}$ and $v_{k}$, respectively. The level of coordinated GGLSC ability in this paper is divided into four levels, i.e., Level I, Level II, Level III and Level IV, which correspond to "poor coordinated GGLSC ability", "qualified coordinated GGLSC ability", "good coordinated GGLSC ability" and "excellent coordinated GGLSC ability", respectively. The row vectors $\boldsymbol{A}_{1 j}, \boldsymbol{A}_{2 j}$, $\boldsymbol{A}_{3 j}, \boldsymbol{A}_{4 j}, \boldsymbol{A}_{5 j}, \boldsymbol{A}_{6 j}, \boldsymbol{A}_{7 j}(j=1,2,3,4)$ are the membership vector of fuzzified evaluation indexes corresponding to the $j$ th coordinated GGLSC ability level. $\beta$ is membership vector of the weighted evaluation indexes. $\boldsymbol{B}$ is the level of the coordinated GGLSC ability.

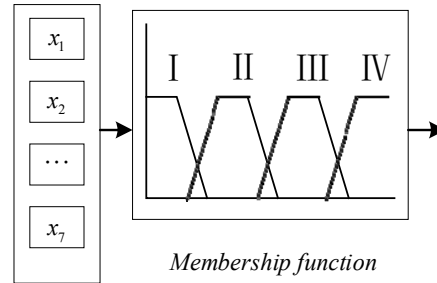

Membership function

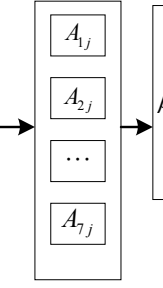

Figure 1. Fuzzy rules in this paper.

combination of the objective weight and the subjective weight to construct the comprehensive weight of the evaluation indexes.

The objective weights are calculated using the antientropy method [20]. Assume that the evaluation matrix

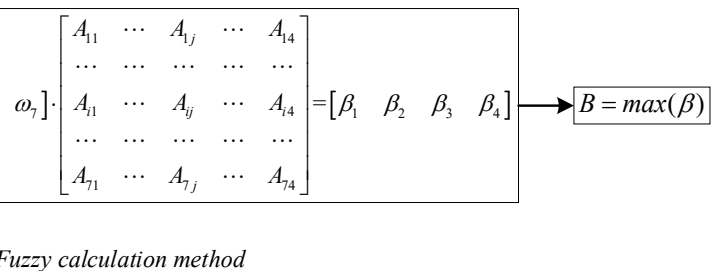

Fuzzy calculation method
Due to the different importance of different evaluation indexes, weight $\omega_{i}$ is used to distinguish the importance of different evaluation indexes. This paper uses the 
of the proposed indexes is $M=\left(x_{i j}\right)_{n \times m}$, the antientropy value of each index can be calculated as follows:

$$
h_{i}=-\sum_{j=1}^{m} r_{i j} \times \ln \left(1-r_{i j}\right)
$$

where $r_{i j}=x_{i j} / \sum_{j=1}^{m} x_{i j}$. The objective weight of index $i$ can be obtained by normalizing the anti-entropy value.

$$
\omega_{o i}=h_{i} / \sum_{i=1}^{n} h_{i}
$$

The subjective weight of the experts is determined by the analytic hierarchy process method (AHP) [21]. Let the comparative matrix based on the three-demarcation [21] method be $N$. The subjective weight $\omega_{s i}$ of index $i$ is obtained as follows:

$$
\omega_{s i}=\xi_{i} / \sum_{i=1}^{n} \xi_{i}
$$

where the $\xi_{i}$ is obtained based on the following method: firstly, obtain the maximum eigenvalue $\lambda_{\max }$ of the comparison matrix $N$ and the corresponding eigenvector vector $\xi$ (whose $i$-th element is $\xi_{i}$ ). Then a consistency check is performed. If the consistency check is passed, the subjective weight $\omega_{s i}$ is accepted; otherwise, reconstruct the comparison matrix $N$ and repeat the previous process until the consistency test is passed.

After calculating the objective and subjective weights, the weight of the evaluation index is calculated as follows [22]:

$$
\varpi_{i}=\omega_{o i}+\eta \omega_{s i} \quad, \quad i=1,2, \cdots, n
$$

where $\eta$ is the coefficient for weighting the corresponding expert experience. The weight of each evaluation index is furthermore normalized to get the comprehensive weight of the evaluation index:

$$
\omega_{i}=\varpi_{i} / \sum_{i=1}^{n} \varpi_{i}
$$

\subsection{The detailed process of the evaluation}

Based on the proposed indexes and method, the coordinated GGLSC ability is evaluated as follows:
1) Calculate the objective weight $\omega_{o i}$ and subjective weight $\omega_{s i}$, and then calculate the comprehensive weight vector $\boldsymbol{\omega}=\left(\begin{array}{lllll}\omega_{1} & \cdots & \omega_{i} & \cdots & \omega_{7}\end{array}\right)$ for the seven evaluation indexes;

2) Based on Latin hypercube sampling [23], several wind speed scenarios and load scenarios are generated according to their probability distributions Then, the wind power is calculated based on the relationship between the wind power and wind speed (see [24]). In this paper, the uncertainties of load and wind speed are described by the normal distribution [25] and the two-parameter Weibull distribution [26], respectively;

3) Calculate the evaluation index for each wind power and load pair. Then the Kmeans clustering algorithm is used to obtain four cluster centers for each index, which are used as a reference for dividing the four evaluation levels;

4) Establish the membership function for each evaluation index;

5) The valuation index $x_{1}, x_{2}, x_{3}, x_{4}, x_{5}, x_{6}$ and $x_{7}$ are calculated based on the predicted wind power and load. After that, calculate the element $A_{i j}$ in the membership matrix of the evaluation index $(i=1,2, \ldots, 7, j=1,2,3,4)$;

6) Calculate $\beta=\omega \cdot A$, and then evaluate the coordinated GGLSC ability by $B=\max (\beta)$. The $B$ is the result of the defuzzification which represents the level of the coordinated GGLSC ability.

\section{Simulation analysis}

\subsection{Test system}

In this section, the IEEE 57 bus system [27] is modified for testing the proposed evaluation method. The modifications include the addition of wind power, battery storage and so on. The detailed modifications are

\begin{tabular}{|c|c|c|c|c|c|c|}
\hline & $\begin{array}{l}\text { HVDC feed-in } \\
\text { power }\end{array}$ & Wind power & $\begin{array}{l}\text { Synchronous } \\
\text { Condenser }\end{array}$ & $\begin{array}{l}\text { Battery } \\
\text { storage }\end{array}$ & Hydropower & Flexible loads \\
\hline AC Bus & 38 & 1 & 38 & 36 & 11 & 29 \\
\hline Capacity & $200 \mathrm{MW}$ & $100 \mathrm{MW}$ & 40MVar & $120 \mathrm{MW}$ & $80 \mathrm{MW}$ & $100 \mathrm{MW}$ \\
\hline
\end{tabular}
shown in Table 1. Note that the wind power is injected into the modified IEEE 57 bus system via HVDC. That means wind power is part of the HVDC feed-in power.

Table 1. Detailed modifications 


\subsection{Evaluation results}

In this section, the coefficient $\eta$ is assumed to be 0.618 . Also, it is assumed that the evaluation matrix $M$ and the comparison matrix $N$ are as follows:

$$
M=\left[\begin{array}{llllllllll}
0.08 & 0.04 & 0.05 & 0.16 & 0.12 & 0.22 & 0.32 & 0.06 & 0.24 & 0.20 \\
0.19 & 0.29 & 0.10 & 0.08 & 0.18 & 0.16 & 0.10 & 0.13 & 0.01 & 0.18 \\
0.18 & 0.05 & 0.13 & 0.18 & 0.08 & 0.08 & 0.23 & 0.03 & 0.03 & 0.24 \\
0.14 & 0.01 & 0.27 & 0.20 & 0.09 & 0.13 & 0.01 & 0.19 & 0.12 & 0.13 \\
0.19 & 0.16 & 0.04 & 0.05 & 0.19 & 0.02 & 0.16 & 0.15 & 0.20 & 0.08 \\
0.18 & 0.26 & 0.23 & 0.24 & 0.08 & 0.20 & 0.12 & 0.22 & 0.25 & 0.03 \\
0.04 & 0.19 & 0.18 & 0.09 & 0.26 & 0.19 & 0.06 & 0.22 & 0.15 & 0.14
\end{array}\right] N=\left[\begin{array}{ccccccc}
1 & 2 & 0 & 2 & 0 & 2 & 2 \\
0 & 1 & 0 & 0 & 1 & 2 & 0 \\
2 & 2 & 1 & 2 & 2 & 1 & 1 \\
0 & 2 & 0 & 1 & 0 & 2 & 1 \\
2 & 1 & 0 & 2 & 1 & 2 & 0 \\
0 & 0 & 1 & 0 & 0 & 1 & 0 \\
0 & 2 & 1 & 1 & 2 & 2 & 1
\end{array}\right]
$$

where the " 0 " in $N$ means that a column element is more according to the (12). Then the objective weight $\omega_{o i}$ is important than a row element, the " 1 " in $N$ means that a column element is as important as a row element, and the " 2 " in $N$ means that a row element is more important than a column element. For example, If the element in the first row and second column is 2 , the element in the second row and first column must be 0 . That is, the second index $\left(x_{2}\right)$ is more important than the first one $\left(x_{1}\right)$. If the element in the seventh row and third column is 1 , then the third index $\left(x_{3}\right)$ is as important as the seventh index $\left(x_{7}\right)$. For the objective weight, the anti-entropy of each index is determined by the evaluation matrix $M$ further calculated by the anti-entropy value according to the (13). For subjective weight, the consistency test of the comparison matrix $N$ is conducted. After the consistency test is passed, the subjective weight of each indexes is determined according to (14). The results of the objective weight and subjective weight can be found in Table 2 in which the numbers 1 to 7 correspond to the evaluation indexes $x_{1}, x_{2}, x_{3}, x_{4}, x_{5}, x_{6}$ and $x_{7}$, respectively.

After that, The comprehensive weights are calculated according to the (15)-(16), whose results are shown in Table 2.

Table 2. Weights of evaluation indexs.

\begin{tabular}{cccccccc}
\hline Evaluated indicators & 1 & 2 & 3 & 4 & 5 & 6 & 7 \\
\hline Objective weight & 0.1527 & 0.1398 & 0.1550 & 0.1509 & 0.1417 & 0.1283 & 0.1316 \\
Subjective weight & 0.1759 & 0.0586 & 0.2647 & 0.0930 & 0.1547 & 0.0575 & 0.1955 \\
Comprehensive weight & 0.1616 & 0.1088 & 0.1969 & 0.1288 & 0.1466 & 0.1013 & 0.1560 \\
\hline
\end{tabular}

After obtaining the comprehensive weight of each evaluation index, the values of the evaluation indexes are calculated for different scenarios of wind power and load which are generated by Latin hypercube sampling [23].
Then the Kmeans clustering analysis is carried out to obtain the clustering centers for different evaluation indexes, whose results are shown in Table 3. The membership function is established based on the Kmeans clustering results of each evaluation index.

Table 3. Kmeans clustering results of evaluation indexes

\begin{tabular}{cccccccc}
\hline Evaluated indicators & 1 & 2 & 3 & 4 & 5 & 6 & 7 \\
\hline I (Class 1) & 0.0372 & 0.2228 & 0.2511 & 43.00 & 0.3734 & 0.0210 & 0.0569 \\
II (Class 2) & 0.0404 & 0.2535 & 0.2732 & 52.10 & 0.4476 & 0.0236 & 0.0675 \\
III(Class 3) & 0.0490 & 0.2792 & 0.3134 & 58.50 & 0.4772 & 0.0271 & 0.0789 \\
IV(Class 4) & 0.0538 & 0.2991 & 0.3390 & 62.40 & 0.5160 & 0.0352 & 0.0902 \\
\hline
\end{tabular}

Three forecasted values of the load and six forecasted values of the wind power are analysed. As shown in Table 4, the coordination control abilities in most cases are in the levels of III and IV. With the increasing wind power and system load, the coordination control ability exhibits a decreasing trend. For example, the coordinated GGLSC abilities are in the levels of II and I when the predicted load is $1632.99 \mathrm{MW}$. When the forecasted load is changed to be $995.3598 \mathrm{MW}$, the coordinated GGLSC control abilities are in the levels of III and IV. 
Table 4. Evaluation results under different scenarios.

\begin{tabular}{ccccccc}
\hline Forecasted wind power & $\begin{array}{l}\# 1 \\
(0 \mathrm{MW})\end{array}$ & $\begin{array}{c}\# 2 \\
(22.9951 \mathrm{MW})\end{array}$ & $\begin{array}{c}\# 3 \\
(52.6294 \mathrm{MW})\end{array}$ & $\begin{array}{c}\# 4 \\
(76.7363 \mathrm{MW})\end{array}$ & $\begin{array}{c}\# 5 \\
(91.6752 \mathrm{MW})\end{array}$ & $\begin{array}{c}\# 6 \\
(100 \mathrm{MW})\end{array}$ \\
\hline $\begin{array}{c}\text { Forecasted load \#1 } \\
(1632.99 \mathrm{MW})\end{array}$ & II & II & II & II & II & I \\
$\begin{array}{c}\text { Forecasted load \#2 } \\
(1313.7 \mathrm{MW})\end{array}$ & III & III & III & III & III & III \\
$\begin{array}{c}\text { Forecasted load \#3 } \\
(995.3598 \mathrm{MW})\end{array}$ & IV & IV & IV & IV & IV & III \\
\hline
\end{tabular}

\section{Conclusion}

In this paper, the fuzzy inference method is used to give a comprehensive evaluation for the coordinated generation-grid-load-storage control ability in the receiving-end power system with HVDC feed-in power. The evaluation indexes are constructed from different aspects such as frequency control and voltage stability level. The modified IEEE 57-bus system is used to test the proposed comprehensive method for evaluating the coordination control ability. This paper can provide a reasonable reference for the development of the coordinated generation-grid-load-storage control strategy.

\section{Acknowledgments}

This paper acknowledges the financial support from the Science and Technology Project of State Grid Hunan Electric Power Company Limited under Grant 5216A518001L.

\section{References}

1. TANG, G., PANG, H., HE, Z. (2016) R\&D and Application of Advanced Power' Transmission Technology in China [J]. Proceedings of the CSEE, 36(7):1760-1771.

2. PENG, L., HE, J., XIE, K., et al. (2017) Comparison of Reliability and Economy Between UHVAC and UHVDC Transmission Systems [J]. Power System Technology, 41(04):1098-1107.

3. CHEN, G., LI, M., XU, T., et al. (2017) Practice and Challenge of Renewable Energy Development Based on Interconnected Power Grids [J]. Power System Technology, 41(10):3095-3103.

4. ZENG, M., YANG, Y., LIU, D., et al. (2016) "Generation Grid Load Storage" Coordinative Otimal Operation Mode of Energy Internet and Key Technologies $[\mathrm{J}]$. Power System Technology ,40(01):114-124.

5. LIU, D., XU, E., XU, X. (2018) "Source-NetworkLoad-Storage" Integrated Operation Model for Microgrid in Park [J]. Power System Technology, 42(03):681-689.

6. ZHENG, M. (2019) Research on Optimal Operation of Hybrid AC/DC Microgrid Considering Sourcenetwork-load-storage Coordination [D]. North China Electric Power University.
7. JIANG, Q., HUANG, K., ZHAO, J., et al. (2020) Study of "Power-Network-Load-Storage" Coordinated Optimization Model for Active Distribution Network Based on Genetic Algorithm [J]. Power and Energy, 41(01):1-5+19.

8. ZENG, M., YANG, Y., XIANG, H., et al. (2016) Optimal Dispatch Model Based on Coordination between "Generation - Grid- Load - Energy Storage" and Demand-side Resource [J]. Electric Power Automation Equipment, 36(02):102-111.

9. LI, K. (2019) Control Method of Energy Storage Participating in Fast Frequency[D].Hunan University.

10. WANG, J., LIU, W., LI, S., et al. (2020) A method to Evaluate Economic Benefits of Power Side Battery Energy Storage Frequency/Peak Regulation Considering The Benefits of Reducing Thermal Power Unit Losses[J/OL].Power System Technology:1-11.

11. CUI, Y., ZHOU, H., ZHOU, W., et al. (2020) Optimal Dispatch of Power System with Energy Storage Considering Deep Peak Regulation Initiative of Thermal Power and Demand Response [J/OL].High Voltage Engineering:1-12.

12. XU, D., WANG, B., ZHANG, J., et al. (2016) Integrated Transmission Scheduling Model for Wind-Photovoltaic-Thermal Power by Ultra-high Voltage Direct Current System[J].Automation of Electric Power Systems, 40(06):25-29+57.

13. XU, H., WANG, Z., CHEN, S., et al. (2020) Study on Control Mode and Networking Performance Optimization of New Generation Condenser at Shaoshan Station [J].Power Capacitor \& Reactive Power Compensation, 41(01):79-85.

14. CUI, T., SHEN, Y., ZHANG, B., et al. (2016) Influences of 300 MVar Synchronous Condensers on the Stabilities of Hunan Power Grid [J]. Hunan Electric Power, 36(03):1-4+8.

15. YI, J., LIN, W., YU, F., et al. Calculation Method of Critical Permeability of New Energy Constrained by Static Voltage Stability[J/OL].Power System Technology .

16. LIU, R., LI, Z., YANG, X., et al. (2019) Optimal Dispatch of Community Integrated Energy System Considering User-side Flexible Load [J]. Acta Energiae Solaris Sinica, 40(10):2842-2850.

17. LI, C., YANG, J., XU, Y., et al. (2017) Application of Comprehensive Fuzzy Evaluation Method on 
Recognition of Voltage Sag Disturbance Sources [J]. Power System Technology, 41(03):1022-1028.

18. CHEN, W., JIANG, Q., CAO, Y. (2005) Voltage Vulnerability Assessment Based on Risk Theory and Fuzzy Reasoning [J].Proceedings of the CSEE, (24):20-25.

19. HE, H., XIAO, X., LI, C., et al. (2020) Fuzzy Reasoning Model for Risk Assessment of Voltage Sag Loss for Sentive Users[J/OL].Proceedings of the CSEE: 1-11.

20. ZHANG, X., GE, S., LIU, H., et al. (2014) Comprehensive Assessment System and Method of Smart Distribution Grid[J].Power System Technology, 38(01):40-46.

21. DENG, H., DAI, D., LI, S. (2017) Comprehensive Operation Risk Evaluation of Overhead Transmission Line based on Hierarchical Analysisentropy Weight Method[J].Power System Protection and Control, 45(01):28-34.

22. DING, M., GUO, Y., ZHANG, J., et al. (2015) Node Vulnerability Assessment for Complex Power Grid Based on Effect Risk Entropy-Weighted Fuzzy Comprehensive Evaluation[J]. Transactions of China Electrotechnical Society, 30(03):214-223.

23. GAO, Y., LI, R., LIANG, H., et al. (2015) Two Step Optimal Dispatch Based on Multiple Scenarios Technique Considering Uncertainties of Intermittent Distributed Generations and Loads in the Active Distribution System[J].Proceedings of the CSEE, 35(007):1657-1665.

24. LIU, J., XU, Q., CHENG, H., et al. (2017) Bi-Level Optimal Renewable Energy Sources Planning Considering Active Distribution Network Power Transfer Capability[J]. Transactions of China Electrotechnical Society, 32(09):179-188.

25. ZHOU, Z., SHU, Y., DONG, C., et al. (2020) Staistical Analysis of Wind Energy Distribution Model[J]. Joural of Applied Statistics and Management, 39(04):584-594

26. HUANG, H., YU, W. (2013) Power Grid Reliability Assessment Considering Probability Distribution of Wind Farm Power Output[J]. Power System Technology, 000(009):2585-2591.

27. Wang, M. (20177) Research on the Solution Strategy of Hour-level Monthly Generation and Purchase Scheduling[D]. Chongqing University. 